\title{
Population genetic structure of Plasmopara viticola in the Western Cape Province of South Africa
}

\author{
TREVOR KOOPMAN ${ }^{1,2}$, CELESTE C. LINDE³, PAUL H. FOURIE1+ AND ADÉLE MCLEOD 1* \\ ${ }^{1}$ Department of Plant Pathology, Stellenbosch University, Private Bag XI, Matieland 7602, South Africa \\ ${ }^{2}$ ARC Infruitec-Nietvoorbij, Private Bag X5026, Stellenbosch 7599, South Africa \\ ${ }^{3}$ School of Botany and Zoology, Faculty of Science, Building 116, Daley Road, Australian National University, Canberra ACT 0200, Australia
}

\section{SUMMARY}

Plasmopara viticola populations in South Africa were studied for two consecutive grape growing seasons, in an organically managed and a conventional fungicide-sprayed vineyard. Three to four samplings in each season were genotyped with four microsatellite markers (GOB, CES, ISA and BER). Population differentiation $(F s t)$ between the conventional fungicide-sprayed vineyard and organically managed vineyard was low (0.004 and $0.016)$ in both growing seasons, suggesting one metapopulation. However, differences in the relative contribution of the predominant and new genotypes to epidemics in the two vineyards suggested that fungicide applications may have selected for reduced pathogen diversity. In both years and vineyards, sexual (oosporic) reproduction and/or migration occurred throughout the year and contributed between 12 and $74 \%$ to the epidemic. Hardy-Weinberg analyses suggest that South African P. viticola populations are randomly mating. Epidemics in both years and vineyards were dominated by one or two genotypes that each contributed between 14 and $67 \%$ to the epidemic through asexual reproduction. The remaining genotypes showed low levels of asexual reproduction, with most genotypes never being able to reproduce asexually. However, for some genotypes asexual reproduction was important, as it enabled survival of the genotypes from one season to the next. In total, ten genotypes were able to survive asexually or vegetatively from one season to the next. The populations were further characterized by the presence of a high frequency of isolates that most likely have elevated ploidy levels.

\footnotetext{
*Correspondence: Tel.: +27 21 8084795; Fax: +27 218084956 ;

E-mail: adelem@sun.ac.za

†Current address: Citrus Research International, Stellenbosch University, Private BagXI, Matieland 7602, South Africa.
}

\section{INTRODUCTION}

Downy mildew, one of the most destructive diseases of grapevines, is caused by the diploid, obligate biotrophic oomycete Plasmopara viticola (Berk et Curt.) Berl. et de Toni (Lafon and Clerjeau, 1994; Wong et al., 2001). Similar to most other oomycetes, P. viticola (kingdom Stramenopila, phylum Oomycota) can reproduce asexually through the production of sporangia that release zoospores, as well as sexually through thick-walled resistant oospores (Förster et al., 1990; Harper et al., 2005; Lafon and Clerjeau, 1994). As $P$. viticola is heterothallic, sexual reproduction can only take place if both mating types (A1 and A2) are present (Wong et al., 2001).

Plasmopara viticola is native to Northern America, from were it was accidentally introduced to Europe and the rest of the world. This introduction in the late 1870 s was indirectly due to the devastating root-feeding insect phyloxera (Daktulosphaira vitifoliae), which prompted the replacement of old vines with new vines grafted on to phyloxera-resistant rootstocks from North America that contained downy mildew inoculum (Alexopoulos et al., 1996; Lafon and Clerjeau, 1994). The introduction of $P$. viticola into Europe most probably consisted of more than one introduction event from North America (Gobbin et al., 2006a). In South Africa, downy mildew was officially reported for the first time in 1907 in the Eastern Cape Province, although it was thought to be present in this region prior to the reported date (Dewar, 1907). However, in the largest grapegrowing region in South Africa, the Western Cape Province, the pathogen was not reported until 1968 (Marais, 1973). Subsequent to its report in this region, the pathogen was found sporadically in some regions in the Western Cape, whereas in other regions (Stellenbosch, Wellington, Paarl and Robertson) it was more prevalent and was detected in each of five consecutive growth seasons (Marais, 1973). The source population(s) for the introduction into South Africa is unknown.

World-wide all P. viticola populations, except the North American populations, are considered as founder populations that were founded through the importation of grapevines. Owing to genetic drift and natural selection, all of these populations 
should be characterized by a reduced level of allelic diversity. However, as South African P. viticola populations in the Western Cape Province have only been colonizing grapevines for approximately 39 years (Marais, 1973), compared with 125 years in Europe (Gobbin et al., 2006a), there would have been less opportunities for multiple introductions. Therefore, it is hypothesized that the South African $P$. viticola populations in the Western Cape will have a strong signal of genetic drift. This signal is expected to be even stronger in populations that are subjected to fungicide treatment due to genetic drift and selection. Application of fungicides for which resistance have been reported, including carboxylic acid amides (iprovalicarb, benthiavalicarb, dimethomorph and flumorph) phenylamides (metalaxyl) and cyanoacetamide-oximes (cymoxanil) (Gisi et al., 2007; Gullino et al., 1997; Leroux and Clerjeau, 1985), will most likely result in fixation of alleles in clonal populations leading to adaptation by sorting non-randomly among mutations. Therefore, it can be hypothesized that genetic differentiation will be present between clonally reproducing $P$. viticola populations from vineyards that are managed organically vs. vineyards where fungicides have been applied. If populations are randomly mating, the signal of genetic differentiation among populations will be lost due to random sorting of genes among individuals.

The asexual phase (sporangia), also referred to as secondary inoculum, of $P$. viticola has long been viewed as the life-cycle stage that is most important in causing expansion of epidemics. The pathogen has many asexual cycles during the season under favourable environmental conditions. These cycles result in mass production of inoculum over short time spans, as well as longdistance dispersal of sporangia. By contrast, the role of the sexual phase (oospores) has been primarily viewed as only providing the initial primary inoculum of the epidemic at the start of the season (Blaise et al., 1999; Lafon and Clerjeau, 1994). However, P. viticola population genetic studies in Europe, mainly using microsatellite markers but also randomly amplified polymorphic DNA (RAPD) markers, have recently challenged these long-standing epidemiological views (Gobbin et al., 2006a,b; Stark-Urnau et al., 2000). These studies have concluded that oosporic infections not only contribute to primary infections, but that they can also contribute significantly (26-78\%) to the development of epidemics throughout the growing season (Gessler et al., 2006; Gobbin et al., 2003b, 2005, 2006a; Rumbou and Gessler, 2004). Furthermore, it has been shown that only a few genotypes will significantly contribute, through asexual reproduction, to expansion of the epidemic, with most genotypes not producing a significant number of secondary infections. Currently, it is hypothesized that long-distance migration of asexual spores are limited (Gessler et al., 2006; Gobbin et al., 2003a,b, 2005, 2006a,b; Rumbou and Gessler, 2004, 2006).

Microsatellite markers for genotyping $P$. viticola isolates have been developed independently by two research groups. The first set of markers was developed by Gobbin et al. (2003a), and consists of five markers containing a range of 2-101 alleles per locus. These markers have been used to study several European populations (Gobbin et al., 2003a,b, 2005; Rumbou and Gessler, 2004, 2006), one North American population (Eugster et al., 2003; Kennelly et al., 2005, 2006) as well as five Australian populations (Hug et al., 2006). Recently, Delmotte et al. (2006a) developed a second set of seven microsatellite markers that contains relatively low levels of polymorphisms, ranging from one to six alleles per locus. These markers have only been used to characterize P. viticola populations on a more limited scale in Europe (1008 lesions) and North American (50 lesions) (Delmotte et al., 2006a,b).

In South Africa, the severity of downy mildew epidemics varies between years, due to substantial variation in climatic conditions (Marais, 1973). In most years, epidemics can be readily controlled due to low precipitation levels and high temperatures. However, in years with high rainfall and lower temperatures explosive epidemics occur that are difficult to control. The relative contribution of sexual and asexual reproduction, as well as migration to the development of epidemics in South Africa is currently unknown. This is an important epidemiological aspect of the disease that will influence management strategies.

The primary focus of this study was to investigate the population genetic structure of $P$. viticola to understand better the biology of the disease in the Western Cape Province of South Africa, by drawing comparisons mainly with populations from Europe. Because of different climatic conditions in South Africa and a younger grape industry, it is likely that the population structure of $P$. viticola is significantly different from European populations. The source population(s) from which the South African population was founded, would also have played an important role in the current population structure. The study was conducted in one organically managed and one conventional fungicide-treated vineyard in two consecutive growing seasons in the Western Cape Province, which is the largest grape-growing region in South Africa. The specific aims of the study were (1) to determine whether these populations are randomly mating, and what the relative contribution of sexual and asexual reproduction and/or migration is to the development of epidemics, (2) to determine whether $P$. viticola genotypes can survive asexually or vegetatively from one season to the next, and (3) to determine whether vineyard management, organic vs. conventional fungicide treatment, will influence the $P$. viticola population structure.

\section{RESULTS}

\section{Weather conditions and development of epidemics}

Downy mildew symptoms appeared at approximately the same time period (beginning to mid October) in the two sampling seasons (2004/05 and 2005/06) after a period of high rainfall (36 
and $60 \mathrm{~mm} /$ day) in September. In general, the 2004/05 season was more conducive to the development of downy mildew than the 2005/06 season. Within the survey period, there were a total number of 13 rain events in 2004/05 and only seven rain events in the 2005/06 season. The average daily temperatures and relative humidity were $18{ }^{\circ} \mathrm{C}$ and $90 \%, 22.2^{\circ} \mathrm{C}$ and $62 \%$, and $24.1^{\circ} \mathrm{C}$ and $50 \%$ at the start (September-October), middle (November-December) and end (January-February) of the 2004/ 05 season, respectively, whereas temperatures and relative humidity were $18.1^{\circ} \mathrm{C}$ and $75 \%, 26.5^{\circ} \mathrm{C}$ and $50 \%$, and $31.2^{\circ} \mathrm{C}$ and $36 \%$ at the corresponding times in the 2005/06 season.

In the organic vineyard, the initiation of epidemics was slow at the beginning of both seasons but increased in severity as the year progressed (Table 1). In both years, approximately $60-90 \%$ of the vines were heavily infected at the end of the season. The epidemic in this vineyard continued into January and February in both years, most likely due to the weekly, alternating application of compost tea and a copper-sulphur mixture that were not effective in stopping expansion of the epidemic.
In the conventional fungicide-managed vineyard, the disease initially progressed at a rapid rate in 2004/05, but was readily controlled with fungicide applications in the middle and at the end of the season. In the 2004/05 season fosetylAl and mancozeb, iprovalicarb and propineb, as well as potassium phosphate were applied. Unfortunately, the exact application time of these fungicides is unknown due to a change in ownership of the farm. In the 2005/06 season the epidemic in the fungicide vineyard was initially slow but became more severe during the middle of the season (November) after which the epidemic stopped. The spray programme during this season consisted of four phosphoric acid and four cymoxanil (cyanoacetamide-oximes) sprays. In both seasons no new or living lesions were found from December through to February, in the conventional fungicide vineyard. This is most likely due to the stringent spray programmes that were applied, along with unfavourable environmental conditions for disease development at the end of November through to January.

Table 1 Occurrence of Plasmopara viticola genotypes and genotypic diversity of populations collected at different sampling times in two consecutive growing seasons in an organic and conventional fungicide-managed vineyard.

\begin{tabular}{|c|c|c|c|c|c|c|c|c|}
\hline Sample & Sampling date & $\begin{array}{l}\text { Lesions } \\
\text { analysed* }\end{array}$ & $\begin{array}{l}\text { Lesions by } \\
\text { predominant } \\
\text { genotype }(\%) \dagger\end{array}$ & $\begin{array}{l}\text { Total no. } \\
\text { genotypes }\end{array}$ & $\begin{array}{l}\text { New } \\
\text { genotypes } \\
(\%) \ddagger\end{array}$ & $\begin{array}{l}\text { Genotypes } \\
\text { causing }> \\
5 \text { lesions (\%) }\end{array}$ & $\begin{array}{l}\text { Lesions by new } \\
\text { genotypes (\%)§ }\end{array}$ & $E_{H} \mathbb{l}$ \\
\hline \multicolumn{9}{|c|}{ Organic vineyard } \\
\hline \multirow[t]{4}{*}{$2004 / 05$} & $1 s t-04 / 10 / 04$ & $16(P)$ & $0(6)$ & 5 & 100 & 0 & 100 & - \\
\hline & $2 \mathrm{nd}-08 / 12 / 04$ & $76(\mathrm{~T})$ & $18(20)$ & 32 & 88 & 6 & 74 & 0.40 \\
\hline & $3 r d-08 / 02 / 05$ & $113(\mathrm{P})$ & $14(12)$ & 53 & 58 & 9 & 30 & 0.38 \\
\hline & Total $\left.\right|^{* *}$ & 205 & $11(13)$ & 71 & - & 8 & - & 0.36 \\
\hline \multirow[t]{5}{*}{$2005 / 06$} & $1 s t-06 / 10 / 05$ & $11(\mathrm{~T})$ & $18(0)$ & 8 & 100 & 0 & 100 & - \\
\hline & $2 n d-14 / 11 / 05$ & $98(\mathrm{~T})$ & $44(7)$ & 27 & 85 & 15 & 48 & 0.37 \\
\hline & $3 r d-28 / 11 / 05$ & $110(P)$ & $21(13)$ & 51 & 69 & 6 & 42 & 0.39 \\
\hline & 4 th-30/01/06 & $97(P)$ & $2(16)$ & 49 & 69 & 10 & 44 & 0.39 \\
\hline & Total & 316 & $22(10)$ & 106 & - & 13 & - & 0.38 \\
\hline \multicolumn{9}{|c|}{ Conventional fungicide vineyard } \\
\hline \multirow[t]{4}{*}{$2004 / 5$} & $1 s t-04 / 10 / 04$ & $64(P)$ & $14(2)$ & 31 & 100 & 3 & 100 & 0.43 \\
\hline & $2 n d-26 / 10 / 04$ & $67(\mathrm{~T})$ & $28(22)$ & 23 & 22 & 9 & 12 & 0.38 \\
\hline & $3 r d-08 / 12 / 04$ & $53(\mathrm{~T})$ & $39(25)$ & 18 & 33 & 28 & 15 & 0.38 \\
\hline & Total & 184 & $27(16)$ & 48 & - & 10 & - & 0.41 \\
\hline \multirow[t]{4}{*}{ 2005/06 } & 1st-06/10/05 & $13(\mathrm{~T})$ & $23(0)$ & 6 & 100 & 0 & 100 & - \\
\hline & $2 n d-14 / 11 / 05$ & $23(\mathrm{~T})$ & $30(17)$ & 11 & 73 & 9 & 39 & 0.26 \\
\hline & $3 r d-28 / 11 / 05$ & $121(\mathrm{~T})$ & $67(2)$ & 17 & 82 & 18 & 28 & 0.25 \\
\hline & Total & 157 & $40(6)$ & 30 & - & 13 & - & 0.25 \\
\hline
\end{tabular}

*Lesions were collected using either a partial (P) or total (T) sampling strategy. During a total sampling strategy all the lesions were collected, whereas in the partial sampling strategy only two lesions were sampled from every second vine.

tNumber of lesions containing the most predominant genotype, followed by the number of lesions caused by the second most dominant genotype in parentheses. ‡Number of genotypes that were not detected in the previous sampling, divided by the total number of genotypes detected for each specific sampling time.

$\S$ Number of lesions caused by new genotypes divided by the total number of lesions of each specific sampling time.

IShannon's equitability index calculated by $H^{\prime} / H_{\max }^{\prime}$, where $H_{\max }^{\prime}=\ln N(N=$ number of individuals in the sample).

${ }^{* *}$ Values represent those from pooled samples. 


\section{Microsatellite amplification}

All loci had two alleles per locus as in a typical diploid system, except GOB for which a relatively high percentage of the genotypes $(41 \%)$ contained three alleles. Genotypes with three alleles at $\mathrm{GOB}$ occurred in similar frequencies in both the organic and the fungicide-managed vineyards. In isolates where three alleles occurred at GOB, the locus was excluded in allele-based analyses, but retained for genotypic analyses (Tables 1 and 3).

\section{Genetic structure in the organic and conventional fungicide managed vineyards}

In total, in the organic vineyard 530 lesions were genotyped in the two seasons, compared with 340 lesions in the fungicidemanaged vineyard. The total number of genotypes detected in the organic vineyard was 71 (out of 206 lesions) and 106 (out of 324 lesions) in the 2004/05 and 2005/06 seasons, respectively, compared with a total number of 48 (out of 183 lesions) and 30 (out of 157 lesions) genotypes in the corresponding seasons in the fungicide managed vineyard (Table 1). In 2004/05, half of the lesions from the first sampling in both vineyards could not be amplified. Therefore, these two samples were considered as sampled partially (Table 1).
The diversity of loci and genotypic diversity were similar in the organic and conventional fungicide treated vineyards. The most diverse locus according to the number of alleles and allelic richness after rarefaction and Nei's gene diversity was GOB, followed by CES. Loci ISA and BER were similar in their diversity (Table 2). Genotypic diversity $\left(E_{H}\right)$ was similar for all populations $(0.36-0.41)$ except for low values obtained in 2005/06 in the fungicide-managed vineyard (0.25) (Table 1).

The percentage of lesions caused by the predominant genotype in individual samples ranged from 2 to $44 \%$ in the organic vineyard and 14 to $67 \%$ in the fungicide-managed vineyard (Table 1). On average across samples within a year, the percentage of lesions caused by the most predominant genotype in the organic vineyard was $11 \%$ in $2004 / 05$ and $22 \%$ in 2005/06. In the fungicide-managed vineyard, this ranged from $27 \%$ in $2004 / 05$ to $40 \%$ in $2005 / 06$ (Table 1).

Spatial-temporal analysis of the predominant genotypes in the organically and conventional fungicide-managed vineyards (Table 1) in each of the growing seasons showed that five of the eight genotypes expanded from an initial focus, with the number of lesions increasing over time with limited dispersal. It should be noted that the first infections caused by one of the predominant genotypes (G1) in the organic vineyard in the 2004/05 season were not detected, probably due to the limited nature of the

Table 2 Number of alleles, dominant alleles, private alleles and gene diversity of Plasmopara viticola populations sampled during different times in an organic and conventional fungicide-managed vineyard in the 2004/05 and 2005/06 grape-growing seasons.

\begin{tabular}{|c|c|c|c|c|c|c|c|c|c|c|c|c|c|c|c|c|c|c|c|c|c|}
\hline \multirow{2}{*}{ Sampling } & & \multicolumn{4}{|c|}{ Number of alleles $(k)$} & \multicolumn{4}{|c|}{ Allelic richness } & \multicolumn{4}{|c|}{ Dominant allele size* } & \multicolumn{4}{|c|}{ Private alleles } & \multicolumn{4}{|c|}{ Gene diversity $†$} \\
\hline & & $k_{I S A}$ & $k_{\mathrm{GOB}}$ & $k_{\text {CES }}$ & $k_{\mathrm{BER}}$ & ISA & GOB & CES & BER & ISA & $\mathrm{GOB}$ & CES & BER & ISA & GOB & CES & BER & ISA & GOB & CES & BER \\
\hline \multicolumn{22}{|c|}{ Organic vineyard } \\
\hline \multirow[t]{4}{*}{$2004 / 05$} & $1 \mathrm{st}$ & 2 & 7 & 5 & 2 & & & & & 144.1 & $369 / 385.8$ & 171 & 180.9 & & & & & 0.18 & 0.84 & 0.72 & 0.32 \\
\hline & 2nd & 2 & 16 & 9 & 2 & & & & & 144.1 & 385.8 & 139 & 180.9 & & 1 & & & 0.29 & 0.84 & 0.79 & 0.37 \\
\hline & $3 r d$ & 3 & 20 & 10 & 2 & & & & & 144.1 & 385.8 & 139 & 180.9 & 1 & 1 & & & 0.37 & 0.88 & 0.78 & 0.29 \\
\hline & Total & 3 & 22 & 11 & 2 & 2.3 & 14.4 & 7.9 & 2.0 & 144.1 & 385.8 & 139 & 180.9 & 1 & 2 & & & 0.32 & 0.88 & 0.80 & 0.34 \\
\hline \multirow[t]{5}{*}{$2005 / 06$} & $1 s t$ & 2 & 6 & 4 & 2 & & & & & 144.1 & 385.8 & 171 & 180.9 & & & & & 0.38 & 0.80 & 0.65 & 0.12 \\
\hline & $2 n d$ & 2 & 13 & 8 & 2 & & & & & 144.1 & 385.8 & 139 & 180.9 & & & & & 0.38 & 0.88 & 0.74 & 0.18 \\
\hline & $3 r d$ & 2 & 13 & 7 & 2 & & & & & 144.1 & 385.8 & 139 & 180.9 & & & & & 0.43 & 0.88 & 0.67 & 0.21 \\
\hline & 4th & 2 & 17 & 8 & 2 & & & & & 144.1 & 385.8 & 139 & 180.9 & & 3 & & & 0.46 & 0.87 & 0.72 & 0.35 \\
\hline & Total & 3 & 21 & 11 & 2 & 2.0 & 12.3 & 6.9 & 2.0 & 144.1 & 385.8 & 139 & 180.9 & & 3 & & & 0.44 & 0.88 & 0.75 & 0.33 \\
\hline \multicolumn{22}{|c|}{ Conventional fungicide vineyard } \\
\hline \multirow[t]{4}{*}{$2004 / 05$} & $1 s t$ & 2 & 14 & 10 & 2 & & & & & 144.1 & 369.3 & 171 & 180.9 & & & & & 0.26 & 0.77 & 0.75 & 0.23 \\
\hline & $2 n d$ & 2 & 16 & 9 & 2 & & & & & 144.1 & 385.8 & 139 & 180.9 & & & & & 0.26 & 0.81 & 0.77 & 0.34 \\
\hline & $3 r d$ & 2 & 11 & 4 & 2 & & & & & 144.1 & 385.8 & 139 & 180.9 & & & 1 & & 0.31 & 0.81 & 0.69 & 0.24 \\
\hline & Total & 2 & 17 & 11 & 2 & 2.0 & 11.0 & 9.1 & 2.0 & 144.1 & 369.3 & 139 & 180.9 & & & 1 & & 0.28 & 0.80 & 0.79 & 0.24 \\
\hline \multirow[t]{4}{*}{$2005 / 06$} & $1 s t$ & 2 & 7 & 5 & 2 & & & & & 144.1 & $369 / 385.8$ & 139/165 & 180.9 & & & & & 0.28 & 0.82 & 0.74 & 0.38 \\
\hline & 2nd & 2 & 12 & 4 & 2 & & & & & 144.1 & 385.8 & 139 & 180.9 & & & & & 0.3 & 0.90 & 0.64 & 0.24 \\
\hline & $3 r d$ & 2 & 14 & 8 & 2 & & & & & 144.1 & 385.8 & 139 & 180.9 & & 1 & & & 0.24 & 0.79 & 0.81 & 0.51 \\
\hline & Total & 2 & 18 & 11 & 2 & 2.0 & 14.0 & 8.5 & 2.0 & 144.1 & 385.8 & 165.0 & 180.9 & & 1 & & & 0.28 & 0.85 & 0.82 & 0.38 \\
\hline
\end{tabular}

*Allele sizes were calibrated according to a set of European Plasmopara viticola isolates (Gobbin et al., 2003a).

†Nei's gene diversity. 


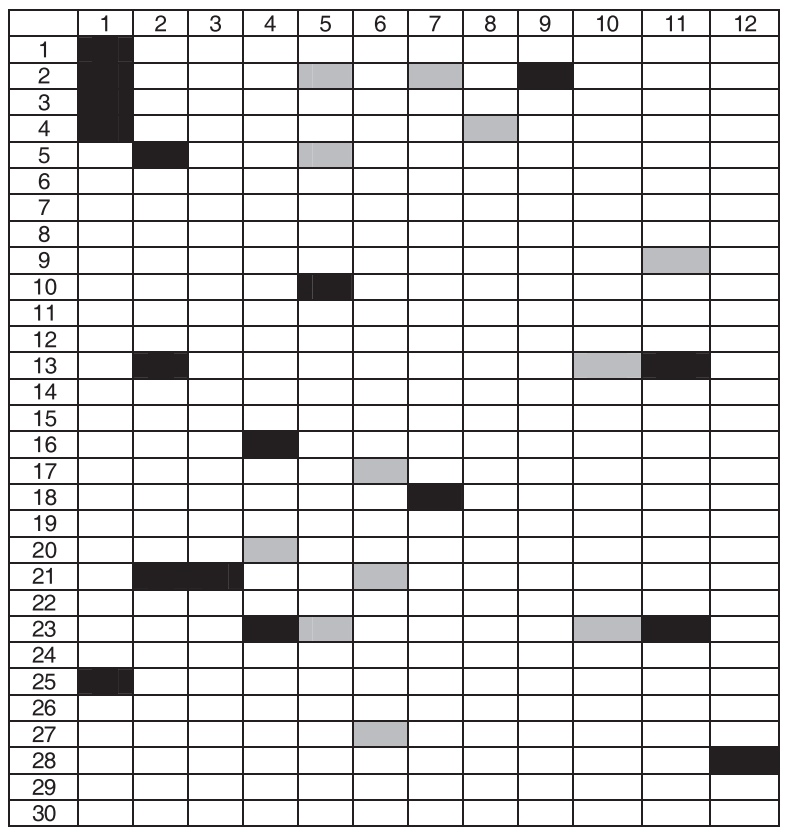

(a) 2004/05 season

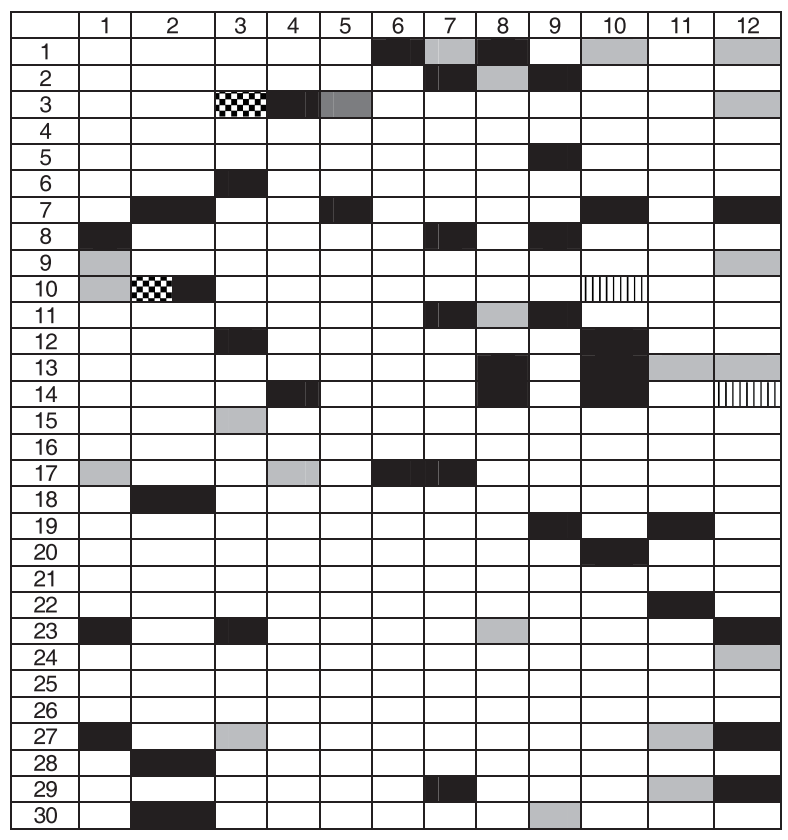

(b) $2005 / 06$ season

Fig. 1 Schematic representation of the predominant genotype G1 in an organically managed vineyard where Plasmopara viticola populations were studied in the (a) 2004/5 and (b) 2005/6 growing seasons. Each square represents one vine, with vines being spaced $2 \mathrm{~m}$ within rows and $3 \mathrm{~m}$ between rows. The dispersion pattern

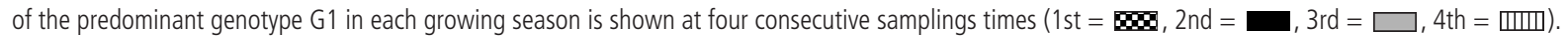

sampling in that epidemic (Table 1, Fig. 1a). The three genotypes that did not show the aforementioned spatial-temporal pattern included genotype $\mathrm{G} 1$ in the organically managed vineyard in the 2005/06 season that initially expanded from a focus, but declined during the epidemic until only two lesions were detected in the fourth sampling (Fig. 1b). Also, the most predominant genotype (G8) in the 2005/06 season in the conventional fungicidemanaged vineyard expanded from a focal point and had a random widespread distribution throughout the plot, whereas the second most predominant genotype in this vineyard and season fluctuated over time. Examples of the spatio-temporal spread of three genotypes in the two vineyards and seasons are represented in Figs 1 and 2.

New genotypes were detected throughout the year with most genotypes, not being able to cause much more than five lesions in each sampling except for the four predominant genotypes (Table 1, column 4). The percentage of lesions caused by new genotypes was higher in samples from the organic vineyard $(30-74 \%)$ than in the fungicide-managed vineyard $(12-39 \%)$ (Table 1). The percentage of new genotypes detected during sampling periods was lowest in the 2nd and 3rd sampling collected in 2004/05 from the conventional fungicide-managed vineyard. The percentage of genotypes causing more than five lesions was highest in the conventional fungicide-managed orchard in the 3rd samplings of both years (Table 1), representing samples taken after five fungicide applications.

\section{Occurrence of genotypes between years and across the two vineyards}

Altogether in the two vineyards, ten genotypes were detected in both seasons, whereas five genotypes were shared among the two vineyards (Table 3). A subset of the lesions containing these genotypes, which were representative of the sampling dates and vineyards, was further genotyped using the microsatellite markers of Delmotte et al. (2006a). These markers also identified the lesions of each of the genotypes (G1-G10) as being clonal. One of the genotypes (G1) was detected in both growing seasons in the organically managed vineyard, and was also the predominant genotype in both seasons in this vineyard (Table 3).

Although six of the genotypes were detected in the organic vineyard as well as in the conventional fungicide-sprayed vineyard in both seasons, some of these genotypes were predominant in the one vineyard, but had a much lower frequency in the other (Table 3). The predominant genotype G10 in the conventional fungicide-sprayed vineyard in the 2005/06 season was also detected in the organic vineyard, but was present at only low frequencies in this vineyard (Table 3). Similarly, the predominant genotype G1 that was present in the organic vineyard in both seasons was only present at a low frequency in the 2004/05 season and absent in the 2005/06 season in the conventional fungicide-managed vineyard (Table 3). The predominant genotype G8 that was present in the 2004/05 season in the conventional 


\begin{tabular}{|c|c|c|c|c|c|c|c|c|}
\hline & 1 & 2 & 3 & 4 & 5 & 6 & 7 & 8 \\
\hline 1 & & & & & & & & \\
\hline 2 & & & & & & & & \\
\hline 3 & & & & & & & & \\
\hline 4 & & & & & & & & \\
\hline 5 & & & & & & & & \\
\hline 6 & & & & & & & & \\
\hline 7 & & & & & & & & \\
\hline 8 & & & & & & & & \\
\hline 9 & & & & & & & & \\
\hline 10 & & & & & & & & \\
\hline 11 & & & & & & & & \\
\hline 12 & & & & & & & & \\
\hline 13 & & & & & & & & \\
\hline 14 & & & & & & & & \\
\hline 15 & & & & & & & & \\
\hline 16 & 8 & & & & & & & \\
\hline 17 & & & & & & & & \\
\hline 18 & & & & & & & & \\
\hline 19 & & & & & & & & \\
\hline 20 & & & & & & & & \\
\hline
\end{tabular}

(a) $2004 / 05$ season

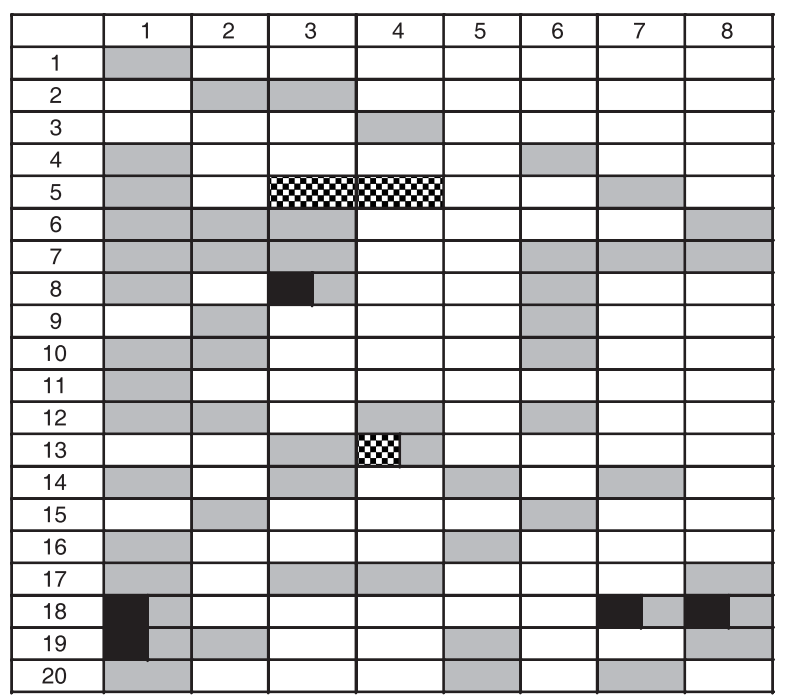

(b) $2006 / 05$ season

Fig. 2 Schematic representation of the predominant genotypes (a) G8 in the 2004/05 growing season and (b) G10 in the 2005/06 growing season in a fungicidemanaged vineyard where Plasmopara viticola populations were studied. Each square represents one vine, with vines being spaced $2 \mathrm{~m}$ within rows and $3 \mathrm{~m}$ between rows. The dispersion pattern of the two predominant $P$. viticola genotypes in each growing season is shown at three consecutive samplings times (1st $=\mathbf{\infty}$ $3 r d=\square$ ).

Table 3 Plasmopara viticola genotypes that were able to survive between seasons (2004/05 and 2005/06) in an organic or conventional fungicide-managed vineyard. The number of lesions of each specific genotype at the $1 \mathrm{st}, 2 \mathrm{nd}$, 3rd or 4 th sampling time within each vineyard and year is shown. The predominant genotypes during 2004/05 were G1 and G7, and G1 and G6 during 2005/06 in the organic vineyard, whereas G8 and G10 were the predominant genotypes in the fungicidemanaged vineyard during the 2004/05 and 2005/06 seasons, respectively.

\begin{tabular}{|c|c|c|c|c|c|c|c|c|c|c|c|c|c|}
\hline \multirow[b]{2}{*}{ Geno. ${ }^{\dagger}$} & \multicolumn{3}{|c|}{ Organic 04/05ł } & \multicolumn{4}{|c|}{ Organic 05/06 } & \multicolumn{3}{|c|}{ Fungicide 04/05 } & \multicolumn{3}{|c|}{ Fungicide 05/06 } \\
\hline & $1 s t$ & 2nd & $3 r d$ & $1 s t$ & 2nd & $3 r d$ & 4 th & $1 s t$ & 2nd & $3 r d$ & 1st & 2nd & $3 r d$ \\
\hline G1 & $0(0)$ & $14(18)$ & $16(14)$ & $2(18)$ & $43(44)$ & $22(20)$ & $2(2)$ & $1(2)$ & $5(8)$ & $3(6)$ & $0(0)$ & $0(0)$ & $0(0)$ \\
\hline $\mathrm{G} 2$ & $0(0)$ & $2(3)$ & $10(9)$ & $1(9)$ & $2(2)$ & $1(1)$ & $0(0)$ & $0(0)$ & $0(0)$ & $0(0)$ & $0(0)$ & $0(0)$ & $0(0)$ \\
\hline G3* & $1(6)$ & $2(3)$ & $3(3)$ & $0(0)$ & $1(1)$ & $1(1)$ & $0(0)$ & $0(0)$ & $0(0)$ & $0(0)$ & $1(8)$ & $0(0)$ & $0(0)$ \\
\hline $\mathrm{G} 4^{*}$ & $0(0)$ & $0(0)$ & $6(5)$ & $1(9)$ & $3(3)$ & $0(0)$ & $0(0)$ & $0(0)$ & $0(0)$ & $0(0)$ & $0(0)$ & $0(0)$ & $0(0)$ \\
\hline G5 & $0(0)$ & $0(0)$ & $1(1)$ & $2(18)$ & $0(0)$ & $0(0)$ & $0(0)$ & $0(0)$ & $0(0)$ & $0(0)$ & $0(0)$ & $0(0)$ & $0(0)$ \\
\hline G6 & $0(0)$ & $3(4)$ & $3(3)$ & $0(0)$ & $6(6)$ & $12(12)$ & $15(15)$ & $0(0)$ & $0(0)$ & $0(0)$ & $0(0)$ & $0(0)$ & $0(0)$ \\
\hline G7 & $1(6)$ & $16(20)$ & $13(12)$ & $0(0)$ & $1(1)$ & $0(0)$ & $0(0)$ & $0(0)$ & $1(2)$ & $2(4)$ & $0(0)$ & $0(0)$ & $0(0)$ \\
\hline G8 & $0(0)$ & $3(4)$ & $0(0)$ & $0(0)$ & $0(0)$ & $0(0)$ & $1(1)$ & $2(3)$ & $19(28)$ & $20(38)$ & $1(8)$ & $0(0)$ & $0(0)$ \\
\hline G9* & $0(0)$ & $2(3)$ & $2(2)$ & $0(0)$ & $5(5)$ & $9(9)$ & $1(1)$ & $1(2)$ & $5(8)$ & $5(10)$ & $1(8)$ & $4(17)$ & $2(2)$ \\
\hline G10 & $0(0)$ & $0(0)$ & $0(0)$ & $0(0)$ & $1(1)$ & $0(0)$ & $3(3)$ & $1(2)$ & $0(0)$ & $2(4)$ & $4(30)$ & $8(34)$ & $80(67)$ \\
\hline
\end{tabular}

†Ten different genotypes (G1 to G10). Genotypes followed by a asterisk contained three alleles at the GOB locus.

$\ddagger$ Values in each column represent the number of lesions with the specific genotype, followed by the percentage of lesions with the specific genotype in brackets.

fungicide-managed vineyard was also present in the organically managed vineyard in both seasons, but remained at low levels (Table 3).

\section{Population subdivision between organic and fungicide-managed vineyards}

Gene diversities were similar in both vineyards. Three private alleles were observed in each sampling year from the organic vineyard, compared with one only in each of the sampling years from the conventional fungicide-managed vineyard (Table 2). No significant population differentiation (Fst) could be observed between sampling years of the organic vineyard or the fungicidetreated vineyard. However, significant Fst values were observed between samples of the organic and fungicide-managed vineyards. This differentiation was mainly due to differences between the 1st sampling in 2004/05 and the 3rd sampling in 2005/06, both from the fungicide-managed vineyard (Table 4). 
Table 4 Estimates of pair-wise Fst values averaged over four microsatellite loci of 13 sampling times in two vineyards.

\begin{tabular}{|c|c|c|c|c|c|c|c|c|c|c|c|c|c|}
\hline & \multicolumn{3}{|c|}{ Organic 04/05 } & \multicolumn{4}{|c|}{ Organic 05/06 } & \multicolumn{3}{|c|}{ Fungicide 04/05 } & \multicolumn{3}{|c|}{ Fungicide 05/06 } \\
\hline & 1 & 2 & 3 & 1 & 2 & 3 & 4 & 1 & 2 & 3 & 1 & 2 & 3 \\
\hline \multirow[t]{3}{*}{ Organic 04/05 } & 1 & & & & & & & & & & & & \\
\hline & 2 & 0.00 & & & & & & & & & & & \\
\hline & 3 & 0.00 & 0.00 & & & & & & & & & & \\
\hline \multirow[t]{4}{*}{ Organic 05/06 } & 1 & 0.00 & 0.00 & 0.00 & & & & & & & & & \\
\hline & 2 & 0.00 & 0.00 & 0.00 & 0.00 & & & & & & & & \\
\hline & 3 & 0.00 & 0.00 & 0.00 & 0.00 & 0.00 & & & & & & & \\
\hline & 4 & 0.00 & 0.00 & 0.00 & 0.00 & 0.00 & 0.00 & & & & & & \\
\hline \multirow[t]{3}{*}{ Fungicide 04/05 } & 1 & 0.00 & 0.03 & $0.05^{*}$ & $0.14^{* *}$ & $0.04^{*}$ & $0.04^{*}$ & $0.09^{* *}$ & & & & & \\
\hline & 2 & 0.00 & 0.02 & $0.05^{*}$ & $0.12^{*}$ & 0.03 & 0.03 & $0.08^{* *}$ & 0.00 & & & & \\
\hline & 3 & 0.00 & 0.00 & 0.00 & 0.03 & 0.00 & 0.00 & 0.02 & 0.00 & 0.00 & & & \\
\hline \multirow[t]{3}{*}{ Fungicide 05/06 } & 1 & 0.00 & 0.00 & 0.00 & 0.00 & 0.00 & 0.00 & 0.00 & 0.04 & 0.03 & 0.00 & & \\
\hline & 2 & 0.00 & 0.00 & 0.02 & 0.05 & 0.00 & 0.00 & 0.03 & 0.00 & 0.00 & 0.00 & 0.00 & \\
\hline & 3 & 0.00 & 0.06 & $0.09 * *$ & $0.20 * *$ & $0.08^{* *}$ & $0.08^{* *}$ & $0.13^{* *}$ & 0.00 & 0.00 & 0.03 & 0.12 & 0.00 \\
\hline
\end{tabular}

${ }^{*} P=0.01,{ }^{*} P=0.05$.

Because of low Fst values in pair-wise comparisons of all samples collected in a specific vineyard and sampled in the same growing season (Table 4), samples were pooled into four populations representing the vineyard and growing season. Significant $(P \leq 0.05)$ Fst values were obtained in all pair-wise comparisons among the four pooled populations, except between populations sampled from the same vineyard in consecutive growing seasons (Table 5). Corresponding $\mathrm{Nm}$ values ranged from 4.2 to 6.9 in pair-wise comparisons among populations from organic and fungicide-managed vineyards (Table 5).

\section{Random mating}

Clone-corrected populations sampled at different sampling times were all analysed for Hardy-Weinberg equilibrium. HardyWeinberg expectations were satisfied for all loci except locus BER in all populations and locus ISA in the 2005/06 organic vineyard with a $G^{2}$ test (Table 6). For the combined populations, also only locus BER was in significant Hardy-Weinberg disequilibrium

Table 5 Estimates of pair-wise Fst (below diagonal) and gene flow ( $\mathrm{Nm}=$ above diagonal) values averaged over four microsatellite loci of two vineyards sampled in consecutive years.

\begin{tabular}{lllll}
\hline & $\begin{array}{l}\text { Organic } \\
04 / 05\end{array}$ & $\begin{array}{l}\text { Organic } \\
05 / 06\end{array}$ & $\begin{array}{l}\text { Fungicide } \\
04 / 05\end{array}$ & $\begin{array}{l}\text { Fungicide } \\
05 / 06\end{array}$ \\
\hline Organic 04/05 & $\mathrm{x}$ & $\sim$ & 6.5 & 6.9 \\
Organic 05/06 & 0.00 & $\mathrm{x}$ & 4.2 & 4.6 \\
Fungicide 04/05 & $0.04^{*}$ & $0.06^{*}$ & $\mathrm{x}$ & $\sim$ \\
Fungicide 05/06 & $0.04^{*}$ & $0.05^{*}$ & 0.00 & $\mathrm{x}$ \\
\hline
\end{tabular}

${ }^{\star} P \leq 0.05$.
(Table 6). Excess heterozygosity (Fis) was observed at loci ISA and BER in both populations (Table 6).

The analysis of molecular variance (AMOVA) showed that $95 \%$ of the genetic diversity observed in the South African $P$. viticola population can be attributed to differences within populations (d.f. $=561$, MS SS $=1445570, P=0.062$ ). None of the variation was due to differences among populations sampled at different times during the growing season (d.f. $=11, \mathrm{SS}=2774, P=0.116$ ), and only $5 \%$ of the variation observed was due to differences between vineyards grown either organically or treated with fungicides (d.f. $=1, \mathrm{SS}=35873, P=0.137$ ).

\section{DISCUSSION}

The population genetic structure of $P$. viticola in South Africa was investigated by genotyping 521 downy mildew lesions from an organically treated vineyard and 341 lesions from a conventional fungicide-treated vineyard with four microsatellite markers. Similar to populations from Europe (Gobbin et al., 2006a), the South African P. viticola populations have high levels of gene diversity, especially for loci GOB and CES, which also have the most alleles and highest allele richness. Furthermore, South African epidemics are also characterized by new infections throughout the growing season, as has been found in Europe (Gobbin et al., 2006a; Rumbou and Gessler, 2004).

This study has revealed negative Fis values $(-0.05$ to -0.47$)$ for three of the four loci analysed. Negative Fis values usually indicate an excess of heterozygosity, consistent with outbreeding, although significant migration among populations will also result in a heterozygosity excess. Fis values were large and positive (0.56-0.74) in all populations sampled for locus BER only. High Fis values indicate a reduction in heterozygosity due to 
Table 6 Observed and expected heterozygosity of the different sampling times during the 2004/05 and 2005/06 seasons in an organically managed and conventional fungicide-treated vineyard.

\begin{tabular}{|c|c|c|c|c|c|c|c|c|c|}
\hline & & \multicolumn{8}{|c|}{ Heterozygosity (observed/expected) } \\
\hline & & \multicolumn{2}{|l|}{ ISA } & \multicolumn{2}{|l|}{ GOB } & \multicolumn{2}{|l|}{ CES } & \multicolumn{2}{|l|}{ BER } \\
\hline & & O/E & Fist & O/E & Fist & O/E & Fist & O/E & Fist \\
\hline \multirow{4}{*}{ Organic 04/05 } & 1 & - & & - & & - & & - & \\
\hline & 2 & $0.35 / 0.30$ & & $1.00 / 0.87$ & & $0.94 / 0.81$ & & $0.10 / 0.37^{* *}$ & \\
\hline & 3 & $0.48 / 0.37$ & & $0.97 / 0.90$ & & $0.98 / 0.79$ & & $0.10 / 0.30^{* *}$ & \\
\hline & Total & $0.40 / 0.33$ & -0.24 & $0.98 / 0.89$ & -0.12 & $0.97 / 0.80$ & -0.21 & $0.10 / 0.34^{* *}$ & 0.74 \\
\hline \multirow[t]{5}{*}{ Organic 05/06 } & 1 & - & & - & & - & & - & \\
\hline & 2 & $0.52 / 0.39^{*}$ & & $0.92 / 0.91$ & & $1.00 / 0.76$ & & $0.04 / 0.18^{* *}$ & \\
\hline & 3 & $0.63 / 0.44^{* *}$ & & $0.87 / 0.91$ & & $0.90 / 0.68$ & & $0.03 / 0.16^{* *}$ & \\
\hline & 4 & $0.73 / 0.47^{* *}$ & & $0.96 / 0.89$ & & $0.93 / 0.73$ & & $0.09 / 0.33^{* *}$ & \\
\hline & Total & $0.66 / 0.45^{* *}$ & -0.47 & $0.91 / 0.89$ & -0.05 & $0.92 / 0.75$ & -0.30 & $0.08 / 0.33^{* *}$ & 0.57 \\
\hline \multirow[t]{4}{*}{ Fungicide 04/05 } & 1 & $0.31 / 0.27$ & & $0.88 / 0.80$ & & $0.88 / 0.79$ & & $0.04 / 0.24^{* *}$ & \\
\hline & 2 & $0.30 / 0.26$ & & $1.00 / 0.84$ & & $1.00 / 0.82$ & & $0.11 / 0.27^{*}$ & \\
\hline & 3 & $0.44 / 0.36$ & & $1.00 / 0.84$ & & $0.94 / 0.72$ & & $0.06 / 0.24^{* *}$ & \\
\hline & Total & $0.40 / 0.33$ & -0.20 & $0.98 / 0.89$ & -0.17 & $0.97 / 0.80$ & -0.18 & $0.10 / 0.34^{* *}$ & 0.74 \\
\hline \multirow[t]{4}{*}{ Fungicide 05/06 } & 1 & - & & - & & - & & & \\
\hline & 2 & - & & & & & & & \\
\hline & 3 & $0.28 / 0.25$ & & $0.85 / 0.82$ & & $0.78 / 0.86$ & & $0.24 / 0.47^{*}$ & \\
\hline & Total & $0.33 / 0.28$ & -0.17 & $0.90 / 0.87$ & -0.08 & $0.85 / 0.83$ & -0.10 & $0.19 / 0.38^{*}$ & 0.56 \\
\hline
\end{tabular}

Loci which were in Hardy-Weinberg disequilibrium with a $G^{2}$ test and 1000 randomizations. ${ }^{*} P=0.05 ;{ }^{* *} P=0.01$.

†Fis = Inbreeding coefficient as determined in POPGENE v 3.2 .

-, Populations with insufficient sample size for HWE analyses.

non-random mating within its subpopulation. Positive estimates of Fis usually indicate an inbreeding mating system. However, positive Fis values may also be recorded in outcrossing populations where there are high frequencies of null alleles at the marker loci used to estimate Fis, and where there is strong population substructure. Significant population structure ( $F s t$ ) was observed between organic and fungicide-managed vineyards, but because BER is the only locus with high positive Fis values, it suggests that null alleles did indeed cause the large positive Fis values at BER. The occurrence of null alleles in $P$. viticola at BER has been suggested previously (Gobbin et al., 2006a). Thus, excluding BER due to the possible occurrence of null alleles at this locus, P. viticola populations from South Africa appear to be randomly mating due to negative Fis values, Hardy-Weinberg equilibrium of the remaining three loci in most populations and high genotypic diversities.

In South Africa, oosporic (sexual) inoculum and/or migration appear to play a role in the development of epidemics throughout the season, given that new genotypes were identified throughout the growing season. The contribution of new genotypes in each sampling to disease development varied from 12 to $74 \%$, with the contribution being the lowest in the 2004/05 conventional fungicide-managed vineyard. These new infections prevailed up until the end of each growing season, causing between 15 and $44 \%$ of the disease incidence. In Europe, Gobbin et al. (2005) and
Rumbou and Gessler (2004) concluded through their microsatellite studies that new genotypes mostly originated from oosporic infections. Kennelly et al. $(2005,2006)$ have recently also shown the importance of oosporic infections through a field infection study where potted seedlings became infected throughout the season upon placement, at 2-5-day intervals, on naturally infected vineyard soil that was removed from the vineyard and placed in a downy mildew-free region. However, even though populations appeared to be in Hardy-Weinberg equilibrium in South Africa, suggesting random mating, we were unable to differentiate whether the new infections were due to immigrants from neighbouring vineyards or indeed oosporic inoculum. The occurrence of the same genotypes between vineyards and seasons suggests that migration also plays a significant role in establishing new infections.

In our study, the ability of genotypes that contributed to epidemics through asexual reproduction appeared to be genotypespecific. In general, only one or two genotypes dominated epidemics in both vineyards and seasons. Only one predominant genotype contributed significantly (67\%) to disease development in only one of the analysed samples. All the predominant genotypes each accounted for a moderate number of lesions (average 6-40\%) throughout the growing seasons. The reported frequency of a specific predominant $P$. viticola genotype varies between vineyards and countries (Gobbin et al., 2006a). 
However, there is a tendency in isolated mountain populations, Greek island and Australian populations for the predominant genotype to contribute to a significant amount of disease (40-94\%) (Gobbin et al., 2003b, 2005, 2006a; Hug et al., 2006; Rumbou and Gessler, 2006). In these populations, there may be little sexual reproduction, or the majority of isolates in a population could have a low fitness, subjecting them to genetic drift during bottlenecks at the end of the growing season, resulting in only one or two predominant genotypes that drive epidemics.

In both analysed vineyards, only a few genotypes (3-28\%) were able to show some low level of asexual reproduction, except for the four predominant genotypes (Table 1, column 4) that showed marked clonal reproduction. Most genotypes were never observed to reproduce asexually. Similar results were found in central Europe, Australia and in Greek populations (Gobbin et al., 2005; Hug et al., 2006; Rumbou and Gessler, 2006, 2007). The limited number of $P$. viticola genotypes that was able to produce more than five lesions through asexual reproduction is surprising, considering that approximately $2.4 \times 10^{5} \mathrm{P}$. viticola sporangia are produced on $1 \mathrm{~cm}^{2}$ of an artificial infected lesion (Reuveni, 2003). Therefore, only a small number of sporangia ultimately seem to succeed in infecting new host material. The reason for this failure may be linked to lower levels of asexual spore production under field conditions, or a high sensitivity of sporangia to unfavourable environmental conditions such as long-wavelength UV light and high temperatures (Mizubuti et al., 2000; Rotem et al., 1985).

The presence of only a limited number of genotypes that are able to reproduce asexually could be due to the genetic background of these isolates. This would suggest that the generation through sexual recombination of a genotype that is also able to reproduce asexually might be a rare event in $P$. viticola. Limited evidence for this can be found in a laboratory study by Kast (2004) and Kast et al. (2001), which showed that $P$. viticola isolates differ in virulence and that not all field lesions are able to produce asexual spores under laboratory conditions. Similar observations were made in this study (unpublished data). In other oomycetes such as Phytophthora infestans, it has indeed been shown that in some sexual crosses the progeny lack pathogenic fitness (Mayton et al., 2000). Furthermore, in P. infestans and P. cinnamomi (soil-borne oomycete), most of the progeny from a sexual cross were found to be significantly less virulent than the parental isolates (Linde et al., 2001; Mayton et al., 2000). Consequently, Mayton et al. (2000) concluded from their study on P. infestans, where laboratory and field inoculations were conducted, that most progeny are not as virulent and fit as the parental strains, and that these will most likely not survive as epidemiologically important individuals. This inability of sexual progeny to survive indicates that genetic inbreeding, which is common in founder populations, may also be present in $P$. viticola populations in
South Africa. Alternatively, the limited observed asexual reproduction could also be due to a limited number of niches, which when occupied by other genotypes will prevent certain genotypes from spreading clonally.

The survival of $P$. viticola genotypes from one season to the next as asexual spores or as vegetative mycelium has only recently been reported from a study in one Greek island population (Rumbou and Gessler, 2006). In South Africa, ten different genotypes survived between seasons in an asexual or vegetative form. Moreover, in the organically managed vineyard, the predominant genotype G1 in the 2004/05 season was able to survive as asexual spores or as vegetative mycelium to the next season (2005/06) where it also dominated the epidemic. It is interesting to note that the spread of the G1 genotype in the 2005/06 season also followed a step-wise dispersal pattern with only two lesions being detected at the start of the season. It is impossible to determine whether these first infections originated from within the sampled block, or whether the surrounding area could have contributed the inoculum. Survival of genotypes between seasons in South Africa might be due to the mild winters, where vegetative mycelium or sporangia may overwinter in grapevine buds or leaves that often remain hanging on the vines until the next season. Another hypothesis for the apparent survival of isolates between seasons could be that the microsatellite markers of Gobbin et al. (2003a) were unable to identify true clonal genotypes in South Africa, due to low levels of polymorphism in two of the tested loci (ISA and BER). However, additional genotyping of these isolates with new markers published by Delmotte et al. (2006a) also identified the specific genotypes as clones. Furthermore, considering the polymorphisms found with both microsatellite marker sets, the estimated number of genotypes that could be detected is $3.6 \times 10^{5}$ (number of allele combinations per locus $=n(n+1) / 2$, where $n=$ number of alleles), which is a considerably higher number than what was detected in this study. We therefore conclude that the isolates are clonal.

The majority of previous $P$. viticola population genetic studies have been conducted in vineyards that were not treated with any fungicides. Where populations were sampled from fungicidetreated vineyards, specific comparisons were not made between treated and untreated vineyards (Gobbin et al., 2005, 2006a; Rumbou and Gessler, 2006). Therefore, this study is the first study attempting to address the effect of fungicide applications on the population structure of $P$. viticola. Population genetic analyses showed that $P$. viticola populations from organic and fungicidetreated vineyards belong to the same metapopulation because (1) there is low population differentiation (Fst) between the conventional fungicide- and organically managed populations $(F s t=0.04-0.06)$, (2) the majority of alleles were shared among populations with only six private alleles in the organic vineyard and two in the fungicide-treated vineyard, and (3) genotypes 
were shared between populations. The sharing of genotypes between the fungicide and organic vineyard, which were separated by $7 \mathrm{~km}$, provides direct evidence for effective genotype flow between vineyards. Nonetheless, it is important to note that the predominant genotype in the organic vineyard was not the predominant genotype in the fungicide-treated vineyard, even though it was present at low frequencies at all 2004/05 sampling times in this vineyard. In addition, the predominant genotypes in the fungicide-treated vineyards contributed more to the epidemic than those in the organic vineyard, suggesting selection of specific genotypes. Furthermore, fewer new genotypes could be detected during the 2004/05 season in the fungicide-treated vineyard, and genotypic diversity in the conventional fungicide-treated vineyard decreased dramatically towards the end of the season in 2005/06. Thus, although the population genetic structure of $P$. viticola supports one metapopulation, there are indications that fungicide applications (iprovalicarb, propineb, cymoxanil, mancozeb and phosphoric acid) reduced pathogen diversity. Further investigations are required in which the fitness and fungicide sensitivity of isolates from both vineyards need to be compared to determine if the reduced pathogen diversity was due to a chance effect or selection for fungicide resistance. In a study on another oomycete, Grünwald et al. (2006) tested the influence of fluazinam, cymoxanil, dimethomorph, metalaxyl and propamocarb fungicide applications on the genetic diversity of $P$. infestans populations in the Toluca valley. In that study, metalaxyl was the only fungicide that resulted in a reduction in genetic diversity of the pathogen (Grünwald et al., 2006). Comparison between this and the $P$. infestans study is difficult as only cymoxanil is shared between the studies and the effect of fungicide applications on the genetic diversity of $P$. infestans populations (Grünwald et al., 2006) was only studied during one field season.

The South African P. viticola populations contained some genotypes $(41 \%)$ that have three alleles at the GOB locus, similar to what has recently been reported in two Greek island populations (Rumbou and Gessler, 2006). However, unlike the Greek island populations, the South African genotypes did not contain three alleles at other loci such as CES and ISA (Rumbou and Gessler, 2006). The presence of three alleles at the GOB locus in some South African genotypes, as well as in two Greek island genotypes (Rumbou and Gessler, 2006), suggests that there is either a gene duplication at this locus, or that the isolates are either triploid $(3 n)$ or trisomic $(2 n+1)$. The presence of only three alleles in all the genotypes, with no genotypes having four alleles, suggests that the genotypes are trisomic rather than triploid. The presence of $P$. viticola isolates with elevated ploidy levels is not unexpected, as it has also been found in other oomycetes including $P$. infestans, $P$. nicotianae, $P$. ramorum and $P$. cinnamomi. In $P$. infestans and $P$. nicotianae the presence of polyploids has been shown through DNA content measurements and cytology (Sansome, 1985; Tooley and Therrien, 1991). The presence of three microsatellite alleles in some $P$. cinnamomi isolates was shown through sexual inheritance studies to be due to partial trisomy in these isolates (Dobrowolski et al., 2002). Furthermore, in P. infestans and $P$. ramorum microsatellite analyses have also identified genotypes with three alleles at some loci (Ivors et al., 2006; Lees et al., 2006), suggesting elevated ploidy levels. However, the trisomic nature of these isolates suggested by the authors still needs to be investigated through sexual inheritance studies (Ivors et al., 2006; Lees et al., 2006).

The presence of $P$. viticola isolates with possible elevated ploidy levels is important, as this could potentially not only influence the success with which isolates reproduce sexually, but also their ability to adapt to environmental conditions (Rumbou and Gessler, 2006). In plants, it has been found that cultivars differing in ploidy level are difficult to cross (Sanford, 1983). Furthermore, Dick (1972) hypothesized that in oomycetes the development of polyploidy and possibly aneuploidy would increase heterozygosity, which could compensate for the loss of evolutionary potential often associated with a fixed genotype. It is noteworthy that two of the most virulent and persistent clonal lineages (US-8 and US-11) of $P$. infestans in the USA are most likely aneuploids (trisomic, $2 n+1$ ) (Fry and Goodwin, 1997; Goodwin et al., 1992), supporting the hypothesis of Rumbou and Gessler (2006) that $P$. viticola isolates with elevated chromosome numbers might have an adaptive advantage. However, although in our study only three of the ten isolates that survived between seasons had three GOB alleles (Table 3), definite conclusions cannot be made since the sample sizes were too small. The generation of oomycete genotypes with elevated chromosome numbers might occur through the production of unreduced gametes, meiotic non-disjunction during sexual reproduction (Dobrowolski et al., 2002; Goodwin et al., 1992) or zoospore fusion (Judelson and Yang, 1998).

The findings from this study, along with those of Rumbou and Gessler $(2006,2007)$, suggest that the population structure and epidemiology of $P$. viticola in warmer climates might be different than what is found in regions with more favourable environmental conditions for disease development. In regions with warmer climates, such as the Greek islands, South Africa and Australia, populations often experience bottlenecks during unfavourable climatic conditions during the growing season, most likely resulting in a strong selection for genotypes capable of surviving adverse environmental conditions. In Australia the absence of oospores in many vineyards (Killigrew and Sivasithamparam, 2005) suggests that epidemics are dominated by highly adapted asexual clonal lineages that can survive between seasons. More populations need to be analysed from South Africa to support this conclusion. Investigations into the frequency and distribution of genotypes that are able to survive as vegetative mycelium or asexual spores will be particularly important in South Africa, as the downy mildew forecasting models that are used currently 
predict the initiation of epidemics based on conditions favourable for oospore germination.

\section{EXPERIMENTAL PROCEDURES}

\section{Vineyard sites}

Downy mildew lesions were collected from two Red Globe vineyards. One vineyard was organically managed with only a copper-sulphur mixture and compost teas being sprayed on an alternating weekly basis, starting at the end of August until the beginning of January. The conventional fungicide-managed vineyard was sprayed with synthetic downy mildew fungicides including fosetyl-Al and mancozeb, iprovalicarb, propineb and potassium phosphate in the $2004 / 05$ season. Unfortunately, the exact time of fungicide applications in this season is unknown due to a change in farm ownership. In the 2005/06 season in the fungicide vineyard, applications commenced at the end of August with a mancozeb application, followed by four applications of a mixture of phosphoric acid and cymoxanil approximately every 2 weeks, until the end of October. The vineyards are situated in the Northern Paarl area (Western Cape province) and are approximately $7 \mathrm{~km}$ apart. The experimental blocks in the organically managed vineyard consisted of 12 rows each containing 30 vines. In the conventional fungicide-managed vineyard, there were eight rows each containing 20 vines. Vine spacing was $2 \mathrm{~m}$ within rows and $3 \mathrm{~m}$ between rows in both vineyards. Weather data, which included hourly temperature, rainfall, leaf wetness and relative humidity, were recorded with a weather station in the organically grown vineyard to estimate infection periods of the disease.

\section{Sampling}

Sampling dates were based on predictions made by the Plant Plus downy mildew forecasting software (Dacom Plant Service, the Netherlands). Downy mildew lesions (known as oil spots) were collected three times during each of the 2004/05 and 2005/06 seasons, with the exception of the organically managed vineyard in which there were four sampling times in the 2005/06 season. Single lesions were sampled by removing a small section of each lesion with a sterilized scissor. The remainder of the lesion was left, allowing the genotype to continue to contribute to the epidemic. The sampled lesions were labelled according to the row, plant and leaf number in order to identify their exact location in the vineyard. The number of lesions collected at each sampling time was determined by the severity of infections, resulting in either a total $(\mathrm{T})$ or partial $(\mathrm{P})$ sampling strategy. A total sampling strategy was followed when the disease incidence was low and all lesions could be collected, whereas a partial sampling strategy was followed at high disease incidences, with only two lesions sampled from every second vine.

\section{DNA isolation}

DNA extraction was done using the Qiagen DNeasy Plant Mini Kit (Qiagen Inc., Valencia, CA). Each sampled lesion was placed in an Eppendorf tube with $0.5-\mathrm{g}$ glass beads ( $2 \mathrm{~mm}$ diameter), and subsequently snap frozen in liquid nitrogen. Lesions were homogenized by shaking the tubes for $10 \mathrm{~min}$ at high frequency (30 1/s) using a Mixer Mill Type MM 301 (Retsch Gmbh \& Co. KG, Germany), equipped with a $2 \times 12$ tube $(1.5 \mathrm{~mL})$ adapter set. Immediately after homogenization, extraction buffer (Gobbin et al., 2003a) was added and tubes were placed at $65^{\circ} \mathrm{C}$ for $10 \mathrm{~min}$, followed by centrifugation for $5 \mathrm{~min}$ at $20000 \mathrm{~g}$ in order to precipitate cellular debris. The cleared supernatant $(350 \mu \mathrm{L})$ was mixed with $525 \mu \mathrm{L}$ of binding buffer AP3/E (Qiagen). The columns were each washed twice with $0.5 \mathrm{~mL}$ AW Buffer (Qiagen), followed by an ethanol wash and membrane drying according to the manufacturer's instructions (Qiagen). DNA was eluted twice with $100 \mu \mathrm{L}$ of sterile distilled water.

\section{Microsatellite amplification}

All sampled lesions (Table 1) were genotyped using microsatellite markers (ISA, GOB, BER, CES) developed by Gobbin et al. (2003a). PCR amplification of ISA and BER was done in a multiplex reaction, whereas GOB and CES were each amplified in single reactions. PCR reactions consisted of a total volume of $10 \mu \mathrm{L}$, containing $5 \mu \mathrm{L}$ DNA solution (not quantified), $1 \times$ Supertherm Gold buffer (Southern Cross Biotechnology Ltd, Cape Town, South Africa), and specific dNTPs, primer, Taq polymerase and $\mathrm{MgCl}_{2}$ concentrations for amplification of each of the different loci. The dNTPs concentration for the ISA and BER multiplex reaction was $0.3 \mathrm{~mm}$, whereas the concentrations for CES and GOB amplifications were 0.4 and $0.3 \mathrm{~mm}$, respectively. The final $\mathrm{MgCl}_{2}$ concentrations for the ISA and BER multiplex reaction was $1.9 \mathrm{mM} \mathrm{MgCl}_{2}$, whereas the concentrations for GOB and CES were 1.9 and $1.8 \mathrm{~mm} \mathrm{MgCl}$, respectively. One unit Taq polymerase (Supertherm Gold, Southern Cross Biotechnology) was used for amplification of GOB, and $0.7 \mathrm{U}$ Taq for CES amplification as well as for the ISA and BER multiplex reaction. Primer concentrations for amplification of the different loci were: $\mathrm{BER}_{\mathrm{f}}, 0.4 \mu \mathrm{m} ; \mathrm{BER}_{\mathrm{r}}$

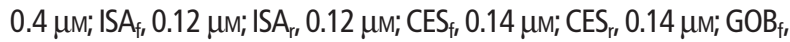
$0.4 \mu \mathrm{m} ; \mathrm{GOB}_{r}, 0.4 \mu \mathrm{m}$. Forward primers were all labelled with the following dyes: $\mathrm{GOB}_{\mathrm{f}}$ and $I \mathrm{SA}_{\mathrm{f}}$ with 6-FAM, $\mathrm{CES}_{\mathrm{f}}$ with VIC and $\mathrm{BER}_{\mathrm{f}}$ with PET (Applied Biosystems, Foster City, CA). PCR was performed in a Gene Amp PCR system 9700 (Applied Biosystems) under the following conditions: 7 min at $95^{\circ} \mathrm{C}, 32$ cycles of $30 \mathrm{~s}$ at $96^{\circ} \mathrm{C}, 30 \mathrm{~s}$ at $60{ }^{\circ} \mathrm{C}$ and $50 \mathrm{~s}$ at $72{ }^{\circ} \mathrm{C}$, with a final extension of 7 min at $72{ }^{\circ} \mathrm{C}$.

A subset of $P$. viticola oil spots, consisting of 64 lesions that were representative of ten specific genotypes obtained from different sampling times, seasons and vineyards (Table 3), were also genotyped using five (Pv7, P13, Pv14, Pv17 and PV31) of the 
seven microsatellite markers developed by Delmotte et al. (2006a). These lesions, which included some of the rare genotypes appearing in either the organic or fungicide vineyard, were genotyped with the additional markers in order to provide additional support that the putative clones that survived between seasons were indeed clonal. PCR amplification of the five markers consisted of two multiplex reactions (Pv17 along with Pv31, and Pv7 along with Pv13), whereas Pv14 were amplified in a single reaction. PCR reactions consisted of a total volume of $10 \mu \mathrm{L}$, containing $5 \mu \mathrm{L}$ DNA solution (not quantified), $1 \times$ Supertherm Gold buffer, $0.7 \cup$ Supertherm Gold Taq, $0.3 \mathrm{~mm}$ dNTPs and specific primer and $\mathrm{MgCl}_{2}$ concentrations for amplification of the different loci. The $\mathrm{MgCl}_{2}$ concentration for the multiplex reactions was $2.5 \mathrm{~mm}$, whereas the concentration for Pv14 amplification was $2 \mathrm{~mm}$. Primer concentrations for amplification of both forward and reverse primers of Pv17, Pv31 and Pv13 were $0.1 \mu \mathrm{m}$, whereas $0.2 \mu \mathrm{m}$ was used for Pv14 and $0.5 \mu \mathrm{m}$ for Pv7 primers. Forward primers were all labelled with the following dyes: Pv7 $7_{f}$ and Pv14 $4_{f}$ with 6-FAM, Pv17 $f$ with VIC, Pv1 $3_{f}$ with PET and Pv31 ${ }_{f}$ with NED (Applied Biosystems). PCR was also performed in a Gene Amp PCR system 9700 (Applied Biosystems) for the multiplex reactions under the following conditions: 2 min at $94{ }^{\circ} \mathrm{C}, 32$ cycles of $30 \mathrm{~s}$ at $95^{\circ} \mathrm{C}, 30 \mathrm{~s}$ at $60^{\circ} \mathrm{C}$ and $30 \mathrm{~s}$ at $72{ }^{\circ} \mathrm{C}$, with a final extension of $2 \mathrm{~min}$ at $72{ }^{\circ} \mathrm{C}$. Amplification conditions for Pv14 were similar as for the multiplex reactions, except that the annealing temperature was $55^{\circ} \mathrm{C}$.

Fragment analysis was performed on an ABI 3100 (Applied Biosystems) genetic analyser. PCR products of GOB (3.5 $\mu \mathrm{L})$, CES $(1.5 \mu \mathrm{L})$ and the ISA and BER multiplex $(1.0 \mu \mathrm{L})$ amplifications were mixed with $8 \mu \mathrm{LdH}_{2} \mathrm{O}$. One microlitre of this mixture was added to $0.5 \mu \mathrm{L} 500 \mathrm{LIZ}^{\mathrm{TM}}$ size standard and $10 \mu \mathrm{L} \mathrm{HiDi}$ (Applied Biosystems) in the sequencing plate. Fragment analysis of the PCR products of the Delmotte et al. (2006a) loci were analysed in a similar manner, except that $1 \mu \mathrm{L}$ of PCR product was diluted in $6 \mu \mathrm{L} \mathrm{dH_{2 }}$ O. Fragments were visualized with Gene Mapper 3.0 ${ }^{\mathrm{TM}}$ (Applied Biosystems). For each locus, different fragment lengths were considered as different alleles. Combining the information provided by the scoring of different loci, samples showing identical allele patterns were interpreted as clonal and thus derivatives of the same oosporic infection.

Allele sizes of the South African populations were calibrated to the allele sizes of published European populations (Gobbin et al., 2003a). This was done by analysing PCR fragments from 30 European genotypes (DNA kindly provided by D. Gobbin, Institute of Integrative Biology, Swiss Federal Institute of Technology, Zürich, Switzerland) on the sequencer used in this study.

\section{Data analyses}

The relative amount of asexual reproduction during the growing season was determined with the Shannon-Wiener index $\left(H^{\prime}\right)$ of genotype richness and evenness in a sample. We specifically used Shannon's equitability index $\left(E_{H}=H^{\prime} / H_{\text {max }}^{\prime}=H^{\prime} / \ln M\right)$ where $N=$ sample size, which is normalized for sample size to account for populations with different sizes. The $E_{H}$ of individual populations (samples) as well as for pooled samples was measured from vineyards collected from a particular growing season.

All other analyses were performed with clone-corrected data sets to prevent over-representation of alleles in frequently occurring clones. Population differentiation ( $F s t)$ (Weir, 1997) between pair-wise comparisons of all populations as well as between pooled samples from vineyards sampled in a particular growing season were conducted in GenALEx 6. Based on low and nonsignificant Fstvalues among samples collected during the same growing season, the samples were pooled to represent only four populations, namely Organic $04 / 05$, Organic $05 / 06$, Fungicide $04 /$ 05 and Fungicide 05/06. These pooled populations were subjected to another clone correction, Fst analyses among populations and also gene flow analyses among populations in GenALEx 6 (Peakall and Smouse, 2001). The allele richness of these four pooled populations was determined in FSTAT as a measure of diversity to compare organic vs. fungicide-managed populations. Because larger populations are more likely to include rare alleles, we analysed the allele richness $R$ after rarefaction to a sample size of the populations with the fewest individuals $(N=23)$ with complete allele information at all loci.

The expected heterozygosity $(\mathrm{He})(\mathrm{Nei}, 1973)$ and the number of alleles and private alleles in individual and pooled populations were determined in POPGENE 3.2 (Yeh and Boyle, 1997). To determine the mating structure and relative contribution of asexual vs. sexual reproduction to the epidemic, departures of Hardy-Weinberg equilibrium were tested in POPGENE 3.2 by testing the significance of association between genotypes at loci in each population with a log-likelihood ratio $G^{2}$ statistic where probability values are obtained with a weighted randomization test. The excess heterozygosity within populations (Fst) (Weir and Cockerham, 1984) was tested with a permutation test (1000 permutations) where alleles were permuted among individuals within the clone-corrected populations.

A hierarchical analyses of molecular variance (AMOVA) was performed in GenALEx 6 (Peakall and Smouse, 2001) to partition the genetic variation. One thousand permutations were performed in the analysis. Hierarchies analysed were within the 13 samples (including different sampling times), among the 13 samples collected throughout the growing season in the two years from the organically and fungicide-treated orchards, and between pooled populations from the organically grown (seven pooled samples) and fungicide-treated vineyards (six pooled samples).

\section{ACKNOWLEDGEMENTS}

We thank the Deciduous Fruit Producers Trust Research and the National Research Foundation for funding the research. We also 
express our thanks to Adriaan Smit and Iwan Labuschagne (Agricultural Research Council, Infruitec-Nietvoorbij) for critical discussion and support of the project.

\section{REFERENCES}

Alexopoulos, C.J., Mims, C.W. and Blackwell, M. (1996) Introductory Mycology. New York: John Wiley \& Sons, Inc.

Blaise, P., Dietrich, R. and Gessler, C. (1999) Vinemild: an application oriented model of Plasmopara viticola epidemics on Vitis vinifera. Acta Hortic. 499, 187-192.

Delmotte, F., Chen, W.J., Richard-Cervera, S., Greif, C., Papura, D., Giresse, X., Mondor-Genson, G. and Corio-Costet, M.F. (2006a) Microsatellite DNA markers for Plasmopara viticola, the causal agent of downy mildew of grapes. Mol. Ecol. Notes, 6, 379-381.

Delmotte, F., Martinez, F., Nemorin, A., Chen, W., Richard-Cervera, S. and Corio-Costet, M.F. (2006b) Spatial genetic structure of grapevine downy mildew epidemic. In: Proceedings of the 5th International Workshop on Grapevine Downy Mildew and Powdery Mildew (Pertot, I., Gessler, C., Gadoury, D., Gubler, W., Kassemeyer, H.H. and Magarey, P., eds) pp. 63. Italy: Litotipografia Alcione.

Dewar, R. (1907) The vine mildew_Plasmopara viticola. Agric. J. Cape Good Hope, 31, 324-329.

Dick, M.W. (1972) Morphology and taxonomy of the oomycetes, with special reference to Saprolegniaceae, Leptomataceae, and Pythiaceae. II. Cytogenetic systems. New Phytol. 71, 1151-1159.

Dobrowolski, M.P., Tommerup, I.C., Blakeman, H.D. and O'Brien, P.A. (2002) Non-medelian inheritance revealed in a genetic analysis of sexual progeny of Phytophthora cinnamomi with microsatellite markers. Fungal Genet. Biol. 35, 197-212.

Eugster, C., Gadoury, D. and Gessler, C. (2003) Relative contribution of oosporic and sporangial inoculum to epidemics of grapevine downy mildew and genetic structure of Plasmopara viticola in a New York Vineyard. Diploma Thesis. Zurich, Switzerland: Phytomedicine/Pathology, Institute of Plant Sciences Swiss Federal Institute of Technology.

Förster, H., Coffey, M.D., Elwood, H. and Sogin, M.L. (1990) Sequence analysis of the small subunit ribosomal RNAs of 3 zoosporic fungi and implications for fungal evolution. Mycologia, 82, 306-312.

Fry, W.E. and Goodwin, S.B. (1997) Re-emergence of potato and tomato late blight in the United States. Plant Dis. 81, 1349-1357.

Gessler, C., Pertot, I. and Gobbin, D. (2006) Genetic structure and epidemiology of Plasmopara viticola populations. In: Proceedings of the 5th International Workshop on Grapevine Downy Mildew and Powdery Mildew.

Gisi, U., Waldner, M., Kraus, N., Dubuid, P.H. and Sierotzki, H. (2007) Inheritance of resistance to carboxylic acid amide (CAA) fungicides in Plasmopara viticola. Plant Pathol. 56, 199-208.

Gobbin, D., Jermini, M., Loskill, B., Pertot, I., Raynal. M. and Gessler. C. (2005) Importance of secondary inoculum of Plasmopara viticola to epidemics of grapevine downy mildew. Plant Pathol. 54, 522-534.

Gobbin, D., Pertot, I. and Gessler, C. (2003a) Identification of microsatellite markers for Plasmopara viticola and establishment of a high throughput method for SSR analysis. Eur. J. Plant Pathol. 109, 153164.

Gobbin, D., Pertot, I. and Gessler, C. (2003b) Genetic structure of a Plasmopara viticola population in an isolated Italian mountain vineyard. J. Phytopathol. 151, 636-646.
Gobbin, D., Rumbou, A., Linde, C.C. and Gessler, C. (2006a) Population genetic structure of Plasmopara viticola after 125 years of colonization in European vineyards. Mol. Plant Pathol. 7, 519-531.

Gobbin, D., Rumbou, A., Pertot, I. and Gessler, C. (2006b) First approach of Plasmopara viticola population biology: merging epidemiology and population genetics. In: Proceedings of the 5th International Workshop on Grapevine Downy Mildew and Powdery Mildew.

Goodwin, S.B., Spielman, L.J., Matuszak, J.M., Bergeron, S.N. and Fry, W.E. (1992) Clonal diversity and genetic differentiation of Phytophthora infestans populations in Northern and central Mexico. Phytopathology, 82, 955-961.

Grünwald, N.J., Sturbaum, A.K., Montes, G.R., Serrano, E.G., LozoyaSaldana, H. and Fry, W.E. (2006) Selection for fungicide resistance within a growing season in field populations of Phytophthora infestans at the centre of origin. Phytopathology, 96, 1397-1403.

Gullino, M.L., Mescalchin, E. and Mezzalama, M. (1997) Sensitivity to cymoxanil in populations of Plasmopara viticola in northern Italy. Plant Pathol. 46, 729-736.

Harper, J.T., Waanders, E. and Keeling, P.J. (2005) On the monopoly of chromalveolates using a six-protein phylogeny of eukaryotes. Int. J. Syst. Evol. Micr. 55, 487-496.

Hug, F., Gobbin, D., Gessler, C. and Magarey, P.A. (2006) Genetic structure and epidemiology of Plasmopara viticola populations from Australian grape growing regions. In: Proceedings of the 5th International Workshop on Grapevine Downy Mildew and Powdery Mildew, pp. 64-65.

Ivors, K., Garbelotto, M., Vries, D.E., Ruyter-Spira, C., Hekkert, T.E., Rosenzweig, N. and Bonants, P. (2006) Microsatellite markers identify three lineages of Phytophthora ramorum in US nurseries, yet single lineages in US forest and European nursery populations. Mol. Ecol. 15, 1493-1505.

Judelson, H.S. and Yang, G. (1998) Recombination pathways in Phytophthora infestans: polyploidy resulting from aberrant sexual development and zoospore-mediated heterokaryosis. Mycol. Res. 102, 1245-1253.

Kast, W.K. (2004) Some results on fungicide resistance of Plasmopara viticola and the influence of genotype fitness. Mitt. Klosterneuburg, 54, 63-66.

Kast, W.K., Stark-Urnau, M., Seidel, M. and Gemmrich, A.R. (2001) Inter-isolate variation of virulence of Plasmopara viticola on resistant vine varieties. Bull. OILB/SROP, 24, 45-49.

Kennelly, M.M., Gadoury, D.M., Seem, R.C., Wilcox, W.F. and Magarey, P.A. (2006) Recent investigations of the biology of Plasmopara viticola: Considerations for forecasting and management of grapevine downy mildew. In: Proceedings of the 5th International Workshop on Grapevine Downy Mildew and Powdery Mildew, pp. 117-119.

Kennelly, M.M., Eugster, C., Gadoury, D.M., Smart, C.D., Seem, R.C., Gobbin, D. and Gessler, C. (2005) Contributions of oospore inoculum to epidemics of grapevine downy mildew (Plasmopara viticola). Phytopathology, 94, S50.

Killigrew, B.X. and Sivasithamparam, K. (2005) Absence of oospores of downy mildew of grape caused by Plasmopara viticola as the source of primary inoculum in most Western Australian vineyards. Plant Dis. 89, 777-777.

Lafon, R. and Clerjeau, M. (1994) Downy mildew. In: Compendium of Grape Diseases (Pearson, R.C. and Goheen, A.C., eds), pp. 11-13. St. Paul, MN: APS Press.

Lees, A.K., Wattier, R., Shaw, D.S., Sullivan, L., William, N.A. and Cooke, D.E.L. (2006) Novel microstellite markers for the analysis of Phytophthora infestans populations. Plant Pathol. 55, 311-319. 
Leroux, P. and Clerjeau, M. (1985) Resistance of Botrytis cinerea Pers. and Plasmopara viticola (Berk. \& Curt.) Berl. \& De Toni to fungicides in French vineyards. Crop Prot. 4, 137-160.

Linde, C., Soo, S.H. and Drenth, A. (2001) Sexual recombination in Phytophthora cinnamomi in vitro and aggressiveness of single-oospore progeny to Eucalyptus. Plant Pathol. 50, 97-102.

Marais, P.G. (1973) Die Biologie en Epidemiologie van Donsskimmel in Wes-Kaapland. MSc Thesis. Stellenbosch, South Africa: University of Stellenbosch.

Mayton, H., Smart, C.D., Moravec, B.C., Mizubuti, E.S.G., Muldoon, A.E. and Fry, W.E. (2000) Oospore survival and pathogenicity of single oospore recombinant progeny from a cross involving US-17 and US-8 genotypes of Phytophthora infestans. Plant Dis. 84, 1190-1196.

Mizubuti, E.S.G., Aylor, D.E. and Fry, W.E. (2000) Survival of Phytophthora infestans sporangia exposed to solar radiation. Phytopathology, $90,78-84$.

Nei, M. (1973) Analysis of gene diversity in subdivided populations. Proc. Natl Acad. Sci. USA, 70, 3321-3323.

Peakall, R. and Smouse, P.E. (2006) GENALEX: genetic analysis in Excel. Population genetic software for teaching and research. Molecular Ecology Notes, 6, 288-295.

Reuveni, M. (2003) Activity of the new fungicide benthiavalicarb against Plasmopara viticola and its efficacy in controlling downy mildew in grapes. Eur. J. Plant Pathol. 109, 243-251.

Rotem, J., Wooding, B. and Aylor, D.E. (1985) The role of solar radiation, especially ultraviolet, in the mortality of fungal spores. Phytopathology, 75, 510-514.

Rumbou, A. and Gessler, C. (2004) Genetic dissection of Plasmopara viticola populations from a Greek vineyard in two consecutive years. Eur. J. Plant Pathol. 110, 379-392.

Rumbou, A. and Gessler, C. (2006) Particular structure of Plasmopara viticola populations evolved under Greek island conditions. Phytopathology, 96, 501-509.

Rumbou, A. and Gessler, C. (2007) Greek epidemics of grapevine downy mildew are driven by local oosporic inoculum: a population biology approach. J. Biol. Res. 7, 3-18.

Sanford, J.C. (1983) Ploidy manipulation. In: Methods of Fruit Breeding (Moore, J.N. and Janick, J., eds), pp. 100-114. West Lafayette, Indiana: Purdue University Press.

Sansome, E. (1985) Cytological studies on Phytophthora nicotianae var. parasitica in relation to mating type. Trans. Br. Mycol. Soc. 84, 87-93.

Stark-Urnau, M., Seidell, M., Kast, W.K. and Gemmrich, A.R. (2000) Studies on the genetic diversity of primary and secondary infections of Plasmopara viticola using RAPD/PCR. Vitis, 39, 163-166.

Tooley, P.W. and Therrien, C.D. (1991) Variation in ploidy in Phytophthora infestans. In: Phytophthora (Lucas, J.A., Shattock, R.C., Shaw, D.S. and Cooke, L.R., eds), pp. 205-217. Cambridge, UK: Cambridge University Press.

Weir, B.S. (1997) Genetic Data Analysis II. Sunderland, MA: Sinauer Associates Inc.

Weir, B.S. and Cockerham, C.C. (1984) Estimating F-statistics for the analysis of population structure. Evolution, 38, 1358-1370.

Wong, F.P., Burr, H.N. and Wilcox, W.F. (2001) Heterothallism in Plasmopara viticola. Plant Pathol. 50, 427-432.

Yeh, F.C. and Boyle, T.J.B. (1997) Population genetic analysis of codominant and dominant markers and quantitative traits. Belg. J. Bot. $129,157$. 